\title{
From reintegrative shaming to restorative institutional hybridity
}

\author{
Miranda Forsyth and Valerie Braithwaite*
}

\section{Introduction}

Crime, shame and reintegration (1989) introduced reintegrative shaming theory in its first iteration, a theory of crime that sought to be integrative and interdisciplinary, normative and explanatory. The normative dimension of the theory is rooted in the republican principle of freedom as non-domination: our institutions, particularly justice institutions, should be cognisant of the goal of reducing the quantum of domination in the world. Domination in the criminal or bullying context often means predation. The principle of freedom as non-domination has been the bedrock of Braithwaite's theories of crime, regulation and society more broadly (Braithwaite \& Pettit, 1990).

This article looks at the evolutionary pathway reintegrative shaming theory has followed from the initial core concepts of shaming, reintegration and stigmatisation. In 2001, a major revision of the theory introduced 30 new propositions for further testing (Ahmed, Harris, Braithwaite \& Braithwaite, 2001). In particular, the concepts of ethical identity, shame and pride management were brought into play. Shame acknowledgement and humble pride in this revision are associated with lower crime, shame displacement (as in blaming others) and narcissistic pride with higher crime. A decade later, a body of knowledge has also accumulated on the role of these core concepts in countries outside the global North. In particular, we explore forgiveness as a ritual of reintegration that has been marginalised in Western-based research but is the spiritual heartland of reintegration in cultures with long histories of change, conflict and adaptation.

Reintegrative shaming theory in its evolving form explains why reshaping institutions to facilitate more effective conflict resolution and healing requires sensitivity to, and engagement with, culture and context. Ultimately, hybridity in institutional design is necessary to give meaning to change and security to transitions. The article also calls for researchers to embrace methodological pluralism in order to appreciate cultural practices that communicate reintegration and stigmatisation in different contexts. Such appreciation is at the heart of learning from each other without pedagogical domination.

* Miranda Forsyth is an Associate Professor at the College of Asia and the Pacific, Australian National University, Canberra, Australia. Valerie Braithwaite is Professor at the College of Asia and the Pacific, Australian National University, Canberra, Australia.

Contact author: Valerie.Braithwaite@anu.edu.au. 


\section{The 2001 revision of reintegrative shaming theory}

The 2001 revision draws heavily on two significant Canberra studies conducted by Nathan Harris (using data from the reintegrative shaming experiments [RISE]) (Harris, 2001a) and Eliza Ahmed (using data from the longitudinal Life at School Survey) (Ahmed, 2001; Ahmed \& Braithwaite, 2012).

In 1989, stigmatisation and reintegration were conceptualised as opposite poles of one dimension. By 2001, empirical research proved this often was not the case - stigmatisation and reintegration could be used to censure unacceptable behaviour either alone or together. Given that stigmatisation increased crime, the implication of the finding was that while institutions needed to be designed to lessen stigmatisation, no assumption could be made that this would automatically enhance reintegration. More detailed testing and theorising followed to understand how to make our institutions more reintegrative.

In the original formulation, reintegrative shaming involves shaming a specific act of wrongdoing while affirming the whole person, leaving open pathways for amends and offering rituals for acceptance and forgiveness that mark re-entry into the community. In the words of an Iranian criminology student, seeking to explain the attraction of reintegrative shaming, '[I]t helps us to trust each other again and have faith in each other even when we do wrong ... with this theory, making wrong or stupid decisions is not the end of the road of one's social life.' Stigmatising shaming, on the other hand, disapproves of and rejects the whole person, closing pathways to redemption within that community. Harris' and Ahmed's work of 2001, while not rejecting these ideas, added complexity. Their empirical research uncovered contexts and histories that afforded offenders different ways of processing regulatory practices of reintegration, which in some cases lead to healing for self and others, but less so in others.

In the 2001 revision, disapproval or shaming was put under the empirical lens independently of whether the message concerned reintegration or stigmatisation. This opened up space to research and theorise the relationship between the regulatory practice of shaming and the personal experience of the emotion of shame and its interpretation. Drawing on Bernard Williams' (1993) work on shame, ethical identity became the lynchpin for processing the emotion of shame and giving it meaning (Harris, 2001b, 2011). Ethical identity represents our 'best self' in terms of capability and goodness. As we discuss below, the concept of ethical identity can also be applied at a level of cultural or national identity, where those designing justice institutions identify the best of existing cultural or religious justice traditions. As a human being we have a conception of our best self. As a group - in the workplace, within a religion, a sport or a nation - we have a 
conception of our best collective identity. ${ }^{2}$ Ethical identity can be destroyed through stigmatised shaming. It is shaken up, socially contested, but rebuilt through reintegrative shaming.

While institutions are powerful in structuring our activity and teaching us how to regulate our and others' behaviour in accord with society's norms, we are not without our own power to resist institutional pressures. People experience shame when they are rejected or disapproved of by others. How they manage shame, that is how they interpret it, is shaped by family, environment and psychological characteristics that extend beyond messages of stigmatisation and reintegration from authorities (Ahmed, 2001).

From the RISE data, Harris was able to show that when people were shamed formally through being arrested for wrongdoing, feelings of shame manifested in three different ways. First was shame-guilt, a surprise to those who wanted to differentiate the inner reflective state of guilt from the externally imposed oppressive state of shame. As social identity theorists have long maintained, the group 'lives' within us - shame-guilt is no exception. However, Harris was also able to find evidence of the more superficial social pressures individuals can feel without internalising them. Shame could take the form of embarrassment and feelings of exposure. Finally, shame could be denied, or bypassed, or more broadly, left unresolved.

Unresolved shame was linked not only to stigmatised shaming, but also to other socially disruptive elements. Those with unresolved shame were less convinced the offence was wrong. Unresolved shame was also likely to be expressed as blame and displaced anger towards others. Repeated encounters with stigmatised shaming (for example, through one's upbringing) combined with too few encounters with law enforcement that were reintegrative invite defensiveness to protect ethical identity - it is too dangerous to acknowledge shame. Protection of ethical identity also necessitates distancing from community standards as hopes to be the better self that others wish becomes a step too far. We also see this with nations: stigmatising nations over human rights' abuses does little to improve human rights standards in such countries.

So where do society's and offenders' hopes for a better outcome lie? Institutionally, disapproval needs to be expressed by people whom an offender respects (not just law enforcement officers), the offender needs to agree that his or her actions have been harmful (agreed societal norms), and the offender needs to perceive institutional shaming as being on balance reintegrative and not stigmatising. These principles are institutionalised in most restorative justice conferences and circles, in many indigenous justice traditions, in the private conversations on

2 We see examples of collective identity at work when businesses own up to misconduct and make amends; when Islamic groups explain the true meaning of the Koran in the face of terrorist acts; when sporting bodies apologise for drug use, a culture of bullying, discrimination, or cheating and take corrective action (as occurred recently with the Australian cricket team); when a nation apologises for actions that have caused harm (New Zealand and mass shootings of worshippers in Christchurch mosques, post-World War II ceremonies of acknowledgement and restitution, national apologies of the kind given by Australia in 2008 to Indigenous peoples for forcibly removing children from their families). 
the international stage of our best diplomats, but not particularly well in traditional Western courtrooms.

\section{What about pride in reintegrative shaming theory?}

While shame is the emotional response to disapproval and broken social ties, pride signals self-worth and secures social bonds. Replacing shame for a bad deed with pride for being a good person is a sign of reintegration, but only under certain conditions. Pride as hubris leads to domination, contrary to the normative intent of reintegrative shaming theory. Pride, therefore, like shame, has a positive and negative face that we need to manage. How we manage shame and pride is shaped by institutions and the opportunities they present for reintegration when harm is done.

Praise is offered explicitly as an adjunct to reintegrative shaming and as an antidote to shaming that has squashed, perhaps inadvertently, all hopes within an ethical identity. However, good shaming and good praise differ. Good shaming is targeted on reintegrative disapproval of an act to give the greatest chance of keeping a whole ethical identity intact. Good praise, in contrast, enfolds the whole person as a virtuous being, in order to strengthen a shaken ethical identity. Good praise elicits pride and strengthens the social bonds that 'anchor' the person and provide supportive social infrastructure as they re-narrate their lives (Ahmed et al., 2001; Maruna, 2001; Zehr, 2000) and come to terms with acts of harm they committed.

Pride that is felt within the company of others and shared with others is defined and measured by Ahmed and Braithwaite (2011) as 'humble pride'. It is as if our ethical identity is not ours alone; it is shared with and protected by others whom we respect and who respect us. Such pride is different from vaunting pride, termed 'narcissistic pride' by Ahmed and Braithwaite (2011), a form of pride that is alienating and aloof from others, and possibly impervious to outside efforts to elicit remorse.

Since 2001, studies in Bangladesh and Australia have shown narcissistic pride and unacknowledged shame are consistently linked with more bullying; humble pride and acknowledged shame with less bullying (Ahmed \& Braithwaite, 2011; Braithwaite \& Ahmed, 2019; Braithwaite, Ahmed \& Braithwaite, 2008). Narcissistic pride and unacknowledged shame are more likely to be found in workplaces where norms of respect for others have been weakened. Institutional arrangements that individualise performance, operate through hierarchy, encourage competition and prevent collective consideration of achievements are congenial to the development of narcissistic pride, not humble pride, and to unacknowledged shame, not acknowledged shame.

Narcissistic pride boosts an ethical identity but disconnects that person and that identity from others. An ethical identity not strengthened or protected by social bonds is brittle. When an ethical identity finds affirmation in narcissistic pride, it will not be receptive to shaming or disapproval. Shaming and disapproval, however packaged, will be highly threatening because without humble 
pride, no one is there to soothe a bruised ethical identity. Regulatory practices of reintegrative shaming have the challenging task of breaking through the shield of pride that fills the holder with a sense of superiority and blamelessness (Braithwaite \& Ahmed, 2019).

This recent research may explain why forgiveness, one of the original rituals of reintegration, along with apology and other reconciliation rituals, infrequently appears as part of the mix in Western societies. If pride is not managed well, and if our institutions encourage narcissistic pride as opposed to humble pride, social bonds will not be robust enough to open one's ethical identity to prospects of giving or wanting forgiveness. In contrast, the offering of forgiveness, along with rehabilitation and reintegration, is important in many other societies, such as Japan, Pakistan, Afghanistan and Melanesia (Braithwaite, 2016). For Bangladeshi children, forgiveness from parents was a more important ritual for preventing school bullying than reintegrative shaming (Ahmed \& Braithwaite, 2005, 2006). A comparative study of the benefits Australians and Japanese saw in the use of restorative justice showed the different value placed on forgiveness. Whereas Australians were more likely to see restorative justice as a means of giving victims voice rather than healing with forgiveness, Japanese considered forgiveness an important benefit (Braithwaite, Huang \& Reinhart, 2013).

Forgiveness, as a sign of healing after harm has occurred, needs institutional settings that bring to the fore relational supports that allow it to sit comfortably within an ethical identity, a conception of best self. This means an ethical identity that is comfortable with seeking forgiveness as well as offering forgiveness. Braithwaite's work in countries across the global South over the past two decades has sought to illustrate which types of institutions nurture forgiveness and other restorative values, and the cultural traditions that inspire inclusion of these values. This is a different type of experimental evidence from the studies discussed above; it involves considering the natural 'experiments' of societies across time and space in developing local practices that reflect wise and just ways of living together. As Braithwaite's work has shown, these natural 'experiments' resonate deeply with the broad principles of reintegrative shaming, providing a form of triangulated support for the theory.

\section{Shame and pride management in restorative justice}

For Braithwaite the essence of restorative justice is healing: healing in the sense of recovery from harm and healing in the sense of prevention of future harm. Both types of healing involve building relationships that recognise the humanity of the other and strengthening bonds of respect and responsibility. There are many theoretical frames for understanding restorative justice conceived both narrowly and broadly. The focus here is on how shame and pride management and reintegration theoretically contribute to understanding restorative justice successes and failures.

In a series of recent papers, Braithwaite reflects on the sites of restorative justice, in its modern sense, and on the more ancient traditions of restorative jus- 
tice, existing along the Silk Road that linked Persia to China (Braithwaite, 2017a, 2017b; Braithwaite \& Gohar, 2014; Wardak \& Braithwaite, 2013a, 2013b). In many ways, Braithwaite himself can be thought of rather as a Silk Road, a living conduit or pathway through which theorising and empirical observations are transported and exchanged. In this journey he reflects on a range of traditions and institutions of social and interpersonal healing that manifest principles of shame and pride management and reintegration.

One important dimension explored is the role of forgiveness, and the institutional structures that enable it. As discussed above, forgiveness conceptually can be understood within a reintegrative shaming theory framework when the victim has the opportunity to shape the ethical identity of the offender. Simultaneously, it provides the victim the opportunity to shape their own ethical identity by showing belief in the offender.

Braithwaite (2016) concluded that although forgiveness occurs only in a small minority of Western restorative justice conferences, it is a significant feature of restorative justice in many countries in the global South. Understanding why this is the case requires a methodology sensitive to context and difference in placing justice traditions within a comparative context. For instance, forgiveness plays a crucial role in Afghanistan, its importance underpinned both by the strong Islamic traditions of forgiveness and traditional cultural justice institutions. The 'weight' of forgiveness is said by some to be so culturally rooted, it is untranslatable. The weight does not come from the words of apology alone, but from the ritual actions that accompany it. At its most profound, this may involve a woman laying her headscarf - which symbolises the 'respect of women' - down on the ground before the victim, to ask for forgiveness. This will occur before a public comprised of family members, respected elders and religious leaders. It can be understood in terms of both shame and pride: the shame comes from publicly 'losing face' in front of a respected audience. The import of this is understood by the victim, who gains pride through the affirmation of an entire community witnessing the offender acknowledging their harm and asking for forgiveness. Through Western eyes, this pride may be suspected of being vaunting and narcissistic, the shame stigmatising. Institutionally what can be learnt, however, is that this cultural ritual has a beginning and end and a humanising dimension. Through this ritual, individuals are placing their ethical identity in the hands of others - not for destruction but rather for safekeeping and future well-being. The result, contrary to Western expectations, is healing through reintegration.

The particular ritual described above may not be one that facilitates defiance and disruption or social change. Rather, as described, it is a ritual of stability that reinforces tradition. The normative question of whether the tradition best enhances the quantum of freedom as non-domination is a relevant question to ask and one that is addressed on Braithwaite's bigger Republican theoretical canvas. The argument we make here is a more specific one about the ethical identity of individuals and groups and how, through comparativism, we learn more about opening ethical identity to outside truths and enabling responsiveness that heals. The implicit criticism of Western scholarship is that we are insufficiently nuanced to detect institutional mechanisms for taking responsibility for the safekeeping of 
another's ethical identity in contexts that at times appear at odds with our ideological dispositions. Too often we see such institutions clearly only when dramatised to suit our own cultural context. In the film Jirga (2018), an Australian soldier returns to Afghanistan to seek forgiveness from the family of a man whom he killed; the same institutional mechanism, a different ideological context.

Importantly, there is nothing superficial or insincere about the quest for forgiveness or its offering in the cases described. Asking for and giving forgiveness require courage through making oneself vulnerable. That said, institutional structures that 'house' forgiveness are inclined to require victims to forgive offenders if and when forgiveness is asked for in a culturally weighted manner. In another example from Afghanistan, known as Nanawate, the offender may come to the victim's house with a sack of flour and a rope around their neck and also around the neck of a goat and present a sword to the victim; theoretically, the victim is free to choose which one to slaughter, but there is cultural pressure to understand that Allah wants us to forgive and our loved ones want us to see the benefits of forgiveness for us. Elders and religious scholars are also likely to present the victim with the Koran open at the page where it states that it is better to forgive than to take revenge. Wardak (2006: 362) observes:

What is important in this ceremony is that the offender is re-accepted into the village after being publicly held responsible, and told that what he/she has done is wrong. But at the same time, he/she is treated with respect as a fellow kinsman.

This example shows how the institutions of Afghan society encourage both the offering of forgiveness and the acceptance of the offender's contrition and the reintegrative role that forgiveness plays in this age-old justice tradition developed and tested over many centuries.

What these observations of reintegrative shaming principles and forgiveness tell us is that culturally meaningful forgiveness has to be buttressed by rituals of practice that genuinely speak to person-to-person and group-to-group connectivity. A comparative perspective suggests that forgiveness is less commonly experienced and valued in the West, because the rituals and institutions for healing in the West lack the social infrastructure that will buttress the kind of connectivity that makes forgiveness safe and genuine for offender and victim. Where pridefulness is institutionalised in an individualistic and hierarchical way, any gesture of forgiveness is likely to ring hollow. We have seen many examples in the media from business executives apologising for financial crises and data privacy breaches to film stars apologising for their sexual predation in response to the \#MeToo Movement.

Institutional contextualisation of the theory has created the greatest scope for reimagining how the theory might be applied through comparative research. It is institutional contextualising that has also ignited the greatest controversy around reintegrative shaming. This goes beyond the debate around forgiveness to the concept of shaming itself. Ruth Benedict popularised the polarisation of shame and guilt through aligning these terms with cultures - America as a guilt 
culture, Japan a shame culture. This polarisation has had far-reaching effects on Western psychology's theorising on these emotions, as in Tangney's (1990) work on personality dispositions of shame proneness and guilt proneness, even through to Nussbaum's (2004) philosophical discussion of shaming and the law.

Shame proneness is a tendency to react to failure by negatively evaluating the whole self. Guilt proneness, on the other hand, is the tendency to react to failure by negatively evaluating one's actions, but not labelling oneself as a complete failure. In this schema, shame is clearly neither an adaptive nor a socially productive disposition. It has been linked with anger and reduced empathy. Guilt is the superior emotion for human adaptation, socially and personally.

Nussbaum's (2004) engagement with shame is in her critique of shame sanctions. Wrapped up with this discourse has been a popularist call for shaming as punishment, using shaming as a weapon in criminal justice to humiliate, ostracise and demonise individuals who have broken society's rules. Shaming within this understanding is to be roundly condemned from Braithwaite's perspective.

Neither the personality of shame proneness nor the practice of shame sanctions is conceptually related to reintegrative shaming as it is practised in many societies, as it is theorised, or with how it is understood in more nuanced literatures (see, for example, Nussbaum, 2004). When we do something wrong and others disapprove, our social bonds are threatened. This is shaming; it is painful and hurts us. We feel bad about ourselves because it challenges our ethical identity. We may change our ethical identity, or we may change our behaviour. All societies need their members to have ethical identities that reflect shared social values and cultural norms and to act in accordance with their ethical identity. In order to live harmoniously in a culture, we submit our ethical identity to that culture, at least in part.

What reintegrative shaming is essentially saying is that within the constraints of an accepted theory of moral character and the social good, shaming can be done in a win-win way for individuals and society. When we shame reintegratively, we avoid the negative consequences that stigmatisation brings. For children who have been shamed in a stigmatising way throughout their lives, their feelings of shame become insurmountable, and Tangney's (1990) shame proneness may well take hold, with adverse consequences. Any disapproval is threatening, feared and fended off. For children who have been shamed reintegratively, mistakes and disapproval for wrongdoing are part of life, and their feelings of shame are managed in a productive way. In Tangney's framework, we would expect them to be more likely to have a guilt proneness personality disposition. Instead of falsely differentiating shame and guilt as feelings of wrongdoing, we should broaden our vision to look at institutions that help us respond to shame productively and not in a way that is damaging to self and others. One existing institutional structure that offers opportunity for steering society's shaming practices in a win-win direction (win for the individual and win for society and the victim) is restorative justice.

Institutions that allow shaming to occur in a win-win fashion have to be transparent and accountable to those without power as well as to those with power, they have to be able to articulate and justify their moral starting point and 
be responsive to changing social conditions. The value in shaming activists who have taken part in the Extinction Rebellion, for instance, is hard to explain in win-win terms. The activists will reject both shaming and feelings of shame. As for society, neither social coherence nor future sustainability will improve as a result. It is clearly a lose-lose scenario.

For this reason, democratising institutions in ways described by Iris Marion Young (2002) and John Dryzek (2000) become an essential adjunct for purposes of contesting and redesigning the substance and contours of theories of moral character and social good that direct decisions about which behaviours are to be disapproved of and sanctioned. Obviously, legal and court systems have a role as well, but as their trustworthiness comes under fire from ordinary citizens, they also are in need of bridges to the public if they are to retain their legitimacy. Braithwaite's personal preference for a republican theory of freedom as non-domination is one place to start, of course. But it is not the only place, nor should it be.

\section{Towards embracing hybridity in restorative justice}

Braithwaite's learnings about forgiveness in the global South have led to deep enrichment of restorative justice theory. It could be argued that Braithwaite's relational understandings of justice were inspired by his early experiences with the Indigenous community in his local football club and a formative period spent in Bougainville (Papua New Guinea) learning about the importance of restoring relationships and mending harm through dialogue (Braithwaite, Dinnen, Allen, Braithwaite \& Charlesworth, 2010). More recently, Braithwaite draws from both Chinese and Islamic justice traditions to develop his argument that principles should be allowed to trump formal legal rules, arguing that just as in Iranian law the principle of azadi means that freedom should be able to trump rules, so should principles of forgiveness and freedom from domination be able to trump proportionality in punishment (Braithwaite, 2017a, 2017b). Another proposition Braithwaite developed (Braithwaite, 2016: 90-91) is that Western restorative justice philosophy would be improved by incorporation into the international human rights regime of an Islamic right of victims of crime to forgive. This would avoid situations where judges reject outcomes arrived at in a restorative manner through dogmatic assertions of punitive orthodoxy.

In reflecting on the methodological pluralism that has enabled this rich crossfertilisation of theory and empirical findings across the globe, it is important to draw attention to the relational approach Braithwaite has developed. It combines personal presence and commitment with the use of the language of restorative justice in an inclusive way. Scholars and practitioners are encouraged jointly to weave together principles of peace, healing and restoration - underpinned by the theory of reintegrative shaming - with principles and values from their cultural, religious and historical traditions. This is support of ethical identity on a different scale - a social or cultural ethical identity - that can at times also involve the processes of re-narration identified by Maruna (2001) and Zehr (2000). As 
Braithwaite (2002: 575) notes, '[there are] grounds for optimism that if we regulate flexibly, being mindful of all the local ideas for innovation, richer models of restorative justice can blossom'. A professor at an Iranian university has observed:

John speaks with a language that everyone around the world can understand ... You know we live in a country with anti-Western attitudes ... but when John came to Iran and spoke ... even those with a strict and fortified position against the West, accepted John's idea since John talked to them with their own language (Personal email to author).

What else could explain that an international conference on restorative justice in Iran in 2018 had to be preceded by 63 sub-conferences across the country to cater for all the scholars and practitioners eager to engage in dialogue about these principles?

One notable feature of the diffusion of restorative justice values and principles along the Braithwaite Silk Road has been the creation of space for pluralism and hybridisation. Offered in non-directive, non-generalised ways, restorative justice thrives in new contexts. Newcomers who encounter it are encouraged to contextualise it within their existing jurisprudential, religious and cultural traditions. The resulting body of theory and praxis can be conceptualised as a vine with deep roots, bearing distinctive fruits in different places. We may find a plum here, a pomegranate there, that can still be connected to the same strong branches of restorative justice. Scholars have noted the problems associated with the rather liquid form of restorative justice as a concept (Strang \& Sherman, 2015), in particular the tendency for it to be used as a label for a wide variety of programmes that do not adhere to either restorative principles or processes. However, our point is that rather than clinging to the one institutional form that has been tested according to rigorous (Northern) criminological standards, there is value in cultivating openness to different varieties and hybrids of restorative justice, and to testing them through methodological pluralism, with the awareness that some may be bitter and better discarded.

Scholars in countries across the Silk Road and beyond such as those cited above have been reflecting deeply on how restorative justice can be used to advance debates about, and bridges between, traditional and religious justice traditions and state justice systems. In many post-conflict and postcolonial societies there is often tension between the desire and the need to draw upon indigenous justice institutions, with their associated accessibility and legitimacy, and concerns that so doing may strengthen patriarchal and discriminatory institutions. Restorative justice has been proposed as a way to escape from the horns of this dilemma. Some see in restorative justice a language that validates the positive underlying values of indigenous justice - its focus on healing of relationships, repairing harm, communal witnessing of acknowledgement of harm and the creation of pathways to move forward - and that balances them with an attentiveness to neutralising power asymmetries and preventing domination. We see a next 
phase of restorative justice development as being the empirical exploration of its potential to fulfil this role.

\section{Conclusion}

Crime, shame and reintegration was the first step in a 30-year journey of learning how to better implement and understand reintegrative shaming as a means of increasing the quantum of freedom as non-domination in the world. The journey has transcended disciplines, marrying psychological, sociological, philosophical, political, criminological, legal and institutional knowledge. Along the way, it has embraced a range of methodological traditions under the guiding principle that methodology should always be in the service of the research question on the table. The journey has prised open the box of Western truisms around justice, suggesting new forms of delivery that better meet human and societal needs. We have shown how the concept of forgiveness is one compelling example that can better inspire Western scholars to find new ways to develop and improve their own justice systems. Perhaps most importantly though, the journey has created national and international networks of scholars, practitioners and others fluently using the shared language of restorative justice in order to name, and better appreciate, those elements of their justice traditions that represent the best side of humanity. Together, we can explore the potential for imagining better and more pluralised justice possibilities across the globe.

\section{References}

Ahmed, E. (2001). Shame management: regulating bullying. In E. Ahmed, N. Harris, J. Braithwaite \& V. Braithwaite (eds.), Shame management through reintegration (pp. 211-311). Cambridge: Cambridge University Press.

Ahmed, E. \& Braithwaite, J. (2005). Forgiveness, shaming, shame and bullying. Australian and New Zealand Journal of Criminology, 38(3), 298-323. doi: 10.1375/acri.38.3.298.

Ahmed, E. \& Braithwaite, J. (2006). Forgiveness, reconciliation, and shame: three key variables in reducing school bullying. Journal of Social Issues, 62(2), 347-370. doi: 10.1111/ j.1540-4560.2006.00454.x.

Ahmed, E. \& Braithwaite, J. (2011). Shame, pride and workplace bullying. In S. Karstedt, I. Loader \& H. Strang (eds.), Emotions, crime and justice (pp. 55-79). Oxford: Hart Publishing.

Ahmed, E. \& Braithwaite, V. (2012). Learning to manage shame in school bullying: lessons for restorative justice interventions. Critical Criminology, 20(1), 79-97. doi: 10.1007/ s10612-011-9151-y.

Ahmed, E., Harris, N., Braithwaite, J. \& Braithwaite, V. (2001). Shame management through reintegration. Cambridge: Cambridge University Press.

Braithwaite, J. (1989). Crime, shame and reintegration. New York: Cambridge University Press.

Braithwaite, J. (2002). Setting standards for restorative justice. British Journal of Criminology, 42, 563-577. doi: 10.1093/bjc/42.3.563. 
Braithwaite, J. (2016). Redeeming the 'F' word in restorative justice. Oxford Journal of Law and Religion, 5, 79-93. doi: 10.1093/ojlr/rwv049.

Braithwaite, J. (2017a). Persia to China: the Silk Road of restorative justice I. Asian Journal of Criminology, 12(1), 23-38. doi: 10.1007/s11417-017-9244-y.

Braithwaite, J. (2017b). Hybrid politics for justice: the Silk Road of restorative justice II. Restorative Justice: An International Journal, 5(1), 7-28. doi: 10.1080/20504721.2017.1294795.

Braithwaite, V. \& Ahmed, E. (2019). Looking beneath the iceberg: can shame and pride be handled restoratively in cases of workplace bullying. The International Journal of Restorative Justice, 2(2), 209-234. doi: 10.5553/ijrj/258908912019002002003.

Braithwaite, V., Ahmed, E. \& Braithwaite, J. (2008). Workplace bullying and victimization: the influence of organizational context, shame and pride. International Journal of Organizational Behaviour, 13(2), 71-94.

Braithwaite, J., Dinnen, S., Allen, M., Braithwaite, V. \& Charlesworth, H. (2010). Pillars and shadows: statebuilding as peacebuilding in Solomon Islands. Retrieved from https:// press.anu.edu.au/publications/series/peacebuilding-compared/pillars-and-shadows (last accessed 17 June 2019).

Braithwaite, J. \& Gohar, A. (2014). Restorative justice, policing and insurgency: learning from Pakistan. Law \& Society Review, 48(3), 531-561. doi: 10.1111/lasr.12091.

Braithwaite, V., Huang, H. \& Reinhart, M. (2013). 'Love thy neighbour' values, needs, and willingness to participate in restorative justice: a survey of Australian and Japanese victims and offenders. Restorative Justice: An International Journal, 1(1), 91-121. doi: 10.5235/20504721.1.1.91.

Braithwaite, J. \& Pettit, P. (1990). Not just deserts: a republican theory of criminal justice. Oxford: Clarendon Press.

Dryzek, J. (2000) Deliberative democracy and beyond: liberals, critics, contestations. Oxford: Oxford University Press.

Harris, N. (2001a). The reintegrative shaming experiment (RISE) and shaming in institutional settings. Retrieved from http://regnet.anu.edu.au/research/research-projects/ details/526/reintegrative-shaming-experiment-rise-and-shaming\#acton-tabs-link--qtresearch_project_details_qtab-ui-tabs1 (last accessed 17 June 2019).

Harris, N. (2001b). Shaming and shame: regulating drink driving. In E. Ahmed, N. Harris, J. Braithwaite \& V. Braithwaite (eds.), Shame management through reintegration (pp. 73-207). Cambridge: Cambridge University Press.

Harris, N. (2011). Shame, ethical identity and conformity: lessons from research on the psychology of social influence. In S. Karstedt, I. Loader \& H. Strang (eds.), Emotions, crime and justice (pp. 193-209). Oxford: Hart Publishing.

Maruna, S. (2001). Making good: how ex-convicts reform and rebuild their lives. Washington: American Psychological Association. doi: 10.1037/10430-000.

Nussbaum, M. (2004). Hiding from humanity: disgust, shame and the law. Princeton: Princeton University Press.

Strang, H. \& Sherman, L. (2015). The morality of evidence: the second annual lecture for Restorative Justice: An International Journal, 3(1), 6-27. doi: 10.1080/20504721.2015.1049869.

Tangney, J.P. (1990). Assessing individual differences in proneness to shame and guilt: development of the self-conscious affect and attribution inventory. Journal of Personality and Social Psychology, 59, 102-111. doi: 10.1037//0022-3514.59.1.102.

Wardak, A. (2006). Structures of authority and local dispute settlement in Afghanistan. In H-J. Albrecht, J.-M. Simon, H. Rezaei, H-C. Rohne \& E. Kiza (eds.), Conflicts and con- 
flict resolution in Middle Eastern societies: between tradition and modernity (pp. 347-370). Berlin: Duncker \& Humblot.

Wardak, A. \& Braithwaite, J. (2013a). Crime and war in Afghanistan Part I: the Hobbesian solution. British Journal of Criminology, 53, 179-196. doi: 10.1093/bjc/azs065.

Wardak, A. \& Braithwaite, J. (2013b). Crime and war in Afghanistan Part II: a Jeffersonian alternative? British Journal of Criminology, 53, 157-214. doi: 10.1093/bjc/azs066.

Williams, B. (1993). Shame and necessity. Berkeley: University of California Press.

Young, I.M. (2002). Inclusion and democracy. Oxford: Oxford University Press.

Zehr, H. (2000). Journey to belonging. A paper delivered at the international conference: just Peace? Peace making and peacebuilding for the new millennium, Massey University, Albany, New Zealand, 24-28 April 2000. Retrieved from https:// www.napierlibrary.co.nz/assets/mcelrea/Journey-to-Belonging-by-Howard-ZehrMassey-University-20000424.pdf (last accessed 17 June 2019). 